\title{
El magnate, nervio del hipersector comunicativo 2.001
}

\author{
Prof. Dr. Pedro Orive Riva \\ Catedrático de Estructura de la Comunicación y Director del Departamento \\ de Periodismo II de la Facultad de Ciencias de la Información
}

\begin{abstract}
Dentro del mundo de las nuevas tecnologías, interesa saber los cambios que éstas están provocando en el Norte y en el Sur. El profesor Orive trata sobre el temor de los países atrasados a perder esta batalla de soportes y contenidos; esta era tecnológica ofrece como auténtica novedad histórica la velocidad de su desarrollo y va a traer consigo «tensiones ciclópeas»; las Nuevas Tecnología de la Información (NTI), permiten un proceso donde lo instantáneo en la obtención de la información se une al volumen de información disponible y a la complejidad de la estructura informativa, que deviene en conglomerados y autopistas de la información. Se trata de un proceso que Pedro Orive define como carrera imparable y apasionante. En ella, tienen un esencial papel los magnates de la informática y de la comunicación. Además, hay que tener en cuenta el cambio que experimentaba el receptor tradicional, que ahora es igualmente, y en cierta manera, proveedor de mensajes.
\end{abstract}

\section{Aceleración de las Turbulencias tecnológicas}

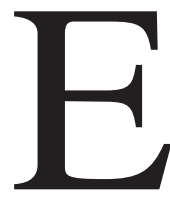

scasos asuntos concitan más interés que enfrentarse al análisis del origen y desarrollo de las turbulencias tecnológicas en el intervalo 1.980-1.998, marcadas por la espectacular velocidad de sus gestaciones, derivadas de la interjección informática-entretenimiento-mediática, las cuales inducen una sorprendente revolución de la información o de los «multimedia», particularmente en los terrenos de la producción y distribución audiovisuales, junto el requerimiento inexcusable de inéditas estrategias de liderato corporativo en el sector.

La informática, avanza sin solución de continuidad, en sus dos fases de hardware y software; el entretenimiento, haciéndolo a expensas del prodigioso desarrollo de las técnicas de vídeo, cine y pluri-televisión (sobre todo la digital, para el próximo trienio); y los medios de comunicación colectiva, integradores de ambas, bajo las especies de interactividad instan- 
tánea y mundialización, fenómenos posibilitadores de mensajes que alcanzan todo el planeta y eliminan haceres de anteriores décadas. «La originalidad de nuestra época reside en que la atención se desplaza del conflicto a la información», en frase de ZELDIN (1997, p.25).

En la delimitación del perturbador intervalo de expansión tecnológica elegido, nos ayudó desde el origen la participación en varias reuniones internacionales y el seguimiento de trabajos de la Intergovernmental Bureau for Informatics (IBI), ubicada en Roma, entre ellos el Informe «Telespín» de 1.980, y en nuestros días, las sugestivas propuestas de la Conferencia Mundial de los Siete Países más Industrializados del Mundo (EE.UU., Japón, Canadá, Alemania, Francia, Reino Unido e Italia), organizada por la Comisión Europea, en Bruselas (24 - 26 /2 - 1.995), que concluyen urgiendo, para primeros de Enero de 1.998, la «liberalización de las Telecomunicaciones».

De un lado, «Telespín» destapa la estrategia de las economías de escala que tienden a concentrar en «países punteros» los grandes Bancos de Datos y la tecnología avanzada, ahondando en su diferencia con los menos desarrollados, excepción de algunos muy peculiares, antes tercermundistas, y ahora super-industrializados, de Extremo Oriente. El G-7, por el otro, acomete el debate inédito del libre acceso de los ciudadanos a la sociedad de la información en el flamante contexto de las autopistas comunicativas y la decidida voluntad de estimular «proyectos» mundiales deseosos de asegurar redes derivadas de la interjección expuesta.

Dentro de este mundo multipolar de influencia sorprendente interesa saber hasta qué extremo las turbulencias tecnológicas están provocando, a la vez, cambios en el Norte y en el Sur, aunque, eso sí, de diferente manera, y en medio del profundo temor de los países atrasados de perder no sólo la batalla de los soportes sino también la de los contenidos. Encrucijada sin salida que hiere las ilusiones de sus gentes, en particular la juventud. Su pobreza la cohibe, cercena e impide desarrollar el potencial energético albergado en sus conciencias.

A lo largo de los diez años que organicé sesiones «ad hoc» en la Conferencia Internacional Informática, con la Fundación CITEMA, en los recintos feriales, primero de la Casa de Campo, y luego del Parque Juan Carlos I, tuve la oportunidad de percibir que las NTI, inductoras de la revolución de la información o de los multimedia, constituyen uno de los principales «centros de interés» de los universitarios actuales, en particular profesores 
y alumnos de las Facultades de Ciencias de la Información, Sociología, Políticas, Psicología e Informática y las Escuelas Técnicas Superiores de Ingenieros de Industria y Telecomunicación.

Ese interés redoblado entre la juventud, surge desde el preciso instante en que al conocer y usar los nuevos descubrimientos, toma consciencia seria de la imposibilidad de aislar los potentes instrumentos de comunicación, resultado de las sofisticadas convergencias tecnológicas, del impacto de los mensajes, cada vez más abundantes, penetrantes, y de modo destacado de la velocidad con que empiezan a gestarse desde mediados del siglo XX.

En ocasiones anteriores, DRUCKER y otros autores, ayudan a percatarnos de que «ni el capitalismo ni las innovaciones técnicas eran algo nuevo: ambos habían sido fenómenos comunes y recurrentes a través de las edades, tanto en el Oeste como en el Este». Lo nuevo -añade aquél- fue la velocidad de su difusión y su alcance mundial en todas las culturas, clases sociales y geografía, factor común de las cuestiones esenciales que desarrollaremos en las páginas siguientes. Celeridad y alcance que «convirtieron a los avances técnicos en la Revolución Industrial, y al capitalismo en el Capitalismo».

Ha bastado sólo centenar y medio de años (1.750-1.900) para posibilitar que «el capitalismo y la tecnología conquistaran al planeta y crearan una civilización mundial». El capitalismo -añade- pasa a convertirse en la propia sociedad y «en vez de estar confinado a una estrecha localidad, como lo había estado siempre, el Capitalismo se impuso en todo el oeste y el norte de Europa hacia 1.850. En otros 50 años se propagó a todo el mundo habitado».

Dentro de semejante evolución histórica se inscribe la Revolución Industrial que trae parejo la «alienación del trabajador en calificativo de Karl Marx»; y luego la Revolución de la Productividad, «que en 75 años convirtió al proletariado en una burguesía de clase media, con ingresos muy cercanos a los de la clase alta». No obstante, preferimos reducirlo a determinados espacios geográficos y puntualizar que la elevación social no fue resultado de la operación automática del capitalismo. Para STRACHEY (1.974,p.2O), «le ha sido impuesta al sistema por el mero poder político y sindical, frente a la más decidida oposición, tanto práctica como teórica».

La precisión se imponía a la hora de situar este ingrediente operativo del capitalismo, que termina desencadenando en nuestros días la derrota de la guerra de clases y el comunismo, estimulando el paso de la era de la calidad a la era de la armonía, lo cual según Armo Penzias, premio Nobel 
de Física (1.978), vicepresidente del Laboratorio Bell, A.T.T., erradicará la contraposición en el ser humano.

Parece meridiano, si se tienen los pies en la tierra, que hasta alcanzar esta meta, habrán de experimentarse tensiones ciclópeas, a resueltas de múltiples factores desencadenantes de más equilibrio (THUROW, 1996,ps. 15-45). Entre ellos, la conversión del mundo comunista al capitalismo actual, el «despegue» de las industrias inteligentes (informatizadas, robotizadas) creadas por el hombre, los cambios demográficos, y la aparición de una economía verdaderamente global.

En el conjunto de Del conjunto de tales factores nos interesa ahora el que aborda las Nuevas Tecnologías de la Información (NTI), lugar de encuentro de industrias informáticas y telecomunicaciones, siendo las emblemáticas las aplicadas a la producción y difusión audiovisuales, objeto de la línea de investigación seguida. Estas se caracterizan de suyo por la búsqueda de sistemas de acceso instantáneo a la información, reduciendo al mínimo las limitaciones de la estructura lineal de la cinta de vídeo y desarrollando sistemas de comprensión más eficaces en la utilización de grandes volúmenes informativos.

Subrayamos los vocablos instantáneo y volúmenes porque ambos, abstracción hecha de sus etiologías, impactan en la médula del funcionamiento de los instrumentos de comunicación colectiva, segmento tradicionalmente autónomo y diferenciado de los servicios de telecomunicaciones, aunque estos días asistamos estupefactos al maridaje de ambos, mediante las autopistas de la información, poderosas redes interactivas construidas para prestar servicios telefónicos y otros distintos, en prioridad la televisión por cable.

Curiosamente el entendimiento entre enfoques capaces de ensamblar requerimientos tecnológicos y humano-sociales, fragua la inquietud que lleva o los más enterados a preguntar sobre quién conforma o quién tiene el poder de los pujantes conglomerados comunicativos. Dos incógnitas inmensas, pues inmenso es el impacto de los sectores involucrados en la expresión «sociedad de la información»: informática, telefonía, electrónica de consumo, medios de comunicación y servicios de entretenimiento (cine, música, vídeo, etc...).

\section{Nuevos líderes corporativos}

La integración del pentagrama de ingredientes, convertida en veta de oro de fabulosos negocios, genera conglomerados de vértigo, voraces, urgidos 
de nuevas ilusiones, ideas y planes operativos de producción y venta, a quienes fatalmente sólo queda el recurso de inventar cosas «sorpresa», si quieren asegurar el ritmo de crecimiento e inundar el mercado a la vez que intentar ganar cuantiosas sumas de dinero en sucesivas operaciones financieras, y en el caso de las autopistas de la información, asegurando inéditos y rentabilísimos «peajes».

Es una carrera imparable, casi suicida -unas veces de acierto y otras no-, apasionante en extremo, determinada y ostigada por la feroz competencia entre empresas y líderes. Pero, a pesar de ello, llena de ingentes posibilidades a quienes estén en condiciones de enfrentar los nuevos desafíos y normas, en medio de las tormentas del mañana, a base de emplear nuevas estrategias y personalidades. Por elevación, los magnates mundiales, han de sobrevivir y crecer sin cesar, obligados a estar en pie de guerra, arrostrar «accidentes» en las mencionadas autopistas, y practicar toda suerte de intuiciones tecnológicas y golpes de efecto financieros.

Un escenario inédito, plegado de trepidantes ejemplos, entre los que destaca, en razón de su magnitud, la «opa» salvaje planteada, en Junio de 1995, por el coloso de la informática IBM a Lotus Development Corporation, adquiriendo la segunda en 3.520 millones de dólares (más de 420.000 millones de pesetas), cantidad que supone 220 millones sobre los ofrecidos en el primer momento.

Para el jefe del equipo Internet de IBM (a través de esta red se planteó la oferta y demás detalles de forma instantánea), en declaraciones al Financial Time, «era muy importante que diéramos la impresión de ser rápidos, gente que responde, abiertos y un poco insolentes». Además, IBM que viene perdiendo poder en el mercado de la expansión de ordenadores personales, al tiempo que se dimensiona Microsoft. ${ }_{2}$ la empresa que Bill Gates ha revolucionado a base de imaginación en el mercado de los soportes lógicos, sólo tenía la salida de quedarse con la última, para así intentar arrinconar a Bill Gates, primera fortuna del mundo ya en el «ranking» de la revista Forbes (12.900 millones de dólares U.S.A.), en julio de 1996.

De la rapidez de las mutaciones de empresas trasnacionales, habla lo sucedido, meses después, al creador de la compañía Microsoft, desbancado de ese primer lugar, y quien le seguía en el «ranking», citado de esta Revista, el inversor Warren Buffet, principal ejecutivo de Berkshire Hatlaway Inc., según publica el rotativo «Usa Today» (28-2-1.996). Con la posterior subida de la cotización de las acciones de Microsoft, la postura de Gates ronda 
entonces los 14.100 millones de dólares, pero las de Berkshire suben un 56\% a lo largo del año pasado, lo que ocasionalmente permite finalmente a Buffet desbancar al ya legendario Gates.

Pasados tres años, ya en nuestras fechas, el propio Gates, creador del lengueje que hace posible el diálogo «hombre-máquina», arrincona la pequeña empresa pionera Netscape -termina enriqueciendo al fundador-, el cual hace en Internet lo que el primero en «Windows»: creación de un lenguaje informático asequible, visual, capaz de facilitar el acceso a los flujos informativos diseminados en la red.

¿Qué armas emplea este popular magnate para el triunfo en el asunto? Sencillo: Microsoft y su programa de navegación por Internet, denominado «Explorer», se anticipa regalándoselo a quien tenga instalado en un ordenador el sistema operativo «Windows 95». Fatalmente, desde ahora pocos navegantes comprarán el de «Netscape» si tienen gratis la oferta de Gates.

En esa alta fiebre de magafusiones, con las subsiguientes rupturas sorpresa, no son extraños el caos y el desconcierto reinantes entre los usuarios de productos audiovisuales, de suyo cada vez más indefensos, pues «puede ocurrir que hoy nos propongan un producto, un sistema, que mañana haya desaparecido mediante una compra, fusión o absorción de compañías». En vista de ello, ¿quién se atreve a adoptar una tecnología, que en poco tiempo puede dejar de desarrollarse, no por obsolescencia técnica, sino por la decisión de un Consejo de Administración de una gran compañía». O, más fácil, debido a dificultades económicas que invalidan la generalización de una rentabilidad sencilla en determinado tiempo.

Diríamos que es un «vivir sin vivir en mí», en sobresalto, justo en las postrimerías del milenio, tiempo donde asistimos, como elemento diferenciador, al aumento de las más inesperadas alianzas entre grandes compañías, fenómeno que acarrea vincular socios de distintos paises y abarcar una amplia gama de funciones y actividades. Se trata de nuevos conglomerados que tienden a ser estratégicos, debido a nacer en respuesta directa de los grandes desafíos planteados por las empresas copartícipes (YOSHINO, Michael y RANGAN, Srinivasa, 1.996, ps.15-30).

A lo largo del último quinquenio, por ejemplo, pasamos de la euforia en pos del Sistema Higt Definition (HDTV), o mejor, Televisión de Alta Definición (TVDA), a casi desecharla ante el elevado coste de los aparatos receptores. Sin embargo ahora, el grupo francés THONSON y el operador 
norteamericano Direct TV, van a lanzar, desde el próximo otoño de 1.998, los primeros programas de esta modalidad televisiva, con una imagen tres veces superior a la realización actual. Prevén dos canales, uno de cine, y otro de retransmisiones de grandes acontecimientos deportivos.

Las sucesivas encrucijadas, aparte cebarse en el uso o no de las innovaciones tecnológicas, extienden su ámbito a las mismas organizaciones. Berlusconi persigue materializar una nueva lógica empresarial, intentando vender la mayor parte de Mediaset, no se sabe si debido a falta de liquidez o al convencimiento de que avanzaría en sus negocios adentrándose en las telecomunicaciones propiamente dichas. Al disponer de la experiencia de su paso por negocios inmobiliarios, cinematográficos, televisivos $\mathrm{y}$, los últimos años, incluso el ejercicio de la política, puede serle atractivo dar el paso adelante del control de redes.

Tamaño paquete de impredecibles turbulencias tecnológicas, actualizadas en la segunda mitad de 1.994 y 1.995 , reflejo visible del carácter estratégico atribuído al sector, produjo caos, vértigo, entre los visitantes de la feria organizada por la Asociación Nacional de Radiodifusores Americanos (NAB), en Las Vegas (10/13-4-1995), al detectar, que como trasfondo, se ha producido «una especie de carrera de contactos multinacionales entre compañías, con el fin de realizar fusiones, absorciones, compras y uniones a riesgo, que permitan lograr posiciones preponderantes en el negocio audiovisual y del «broadcasting».

Además, dichos riesgos, y las incertidumbres acompañados, están llamados a multiplicarse, tras las aludidas uniones estratégicas, en la línea de concitar los focos de decisión tecnológica mundial, aunque lamentablemente de espaldas a los restantes elementos de generación y uso del producto cibernético, como es el caso de aglutinar en las mismas manos las dos fases esenciales del producto informático (hardware y software).

\section{Ruta de los magnates}

Consciente de la envergadura del «corpus», de nuestro estudio, para la vigencia de la democracia avanzada y el sistema mundial de comunicación, inicié en 1.977, en los EE.UU., su exploración «in situ» en la doble vertiente de encontrar nuevas teorías sobre la base de confrontar experiencias empíricas «multimedia». Esta especie de aventura determina el esforzado recorrido por los principales países de los cinco continentes, involucrados en los principales conglomerados, y se hace bajo la denominación «ruta de los magnates». 
El segundo paso es Roma y Londres. En la primera, llego hacia las entrañas de Silvio Berlusconi, coincidiendo con la batalla política para intentar la ruptura del monopolio estatal de radio y televisión (RAI), mediante la colocación sobre el mar, de forma inesperada y traumática, de la primera estación pirata de televisión. Hablo con amigos personales y contrincantes del naciente magnate «a la europea», pero que sin tardar muchos años, empieza a crecer, extendiendo su imperio comunicativo a toda Italia y algunos países extranjeros. Este raro personaje tiene cuerda y va a ser quien más nos ayude a formar criterio sobre innovadoras teorías del «encuentro» medios-política.

Varias estancias intermitentes en Londres, empiezan a familiarizarme con Robert Maxwell, magnate del Grupo «Mirror», llegado de Checoslovaquia, sin nada en las manos, pero que consigue triunfar en los negocios de Gran Bretaña, su país de adopción. Es diputado laborista, se arruina y renace varias veces, para terminar su vida en circunstancias trágicas. El seguimiento de la dura batalla librada con Murdoch por el control del mercado periodístico vespertino londinense es un laboratorio ideal para entender las posibilidades y limitaciones de la prensa en la era digital.

Los negocios británicos de Rupert Murdoch, el australiano de origen, más tarde afincado en EE.UU., Rupert Murdoch, magnate de News Corporation y New International, me predisponen a buscar sus raices, a la vez que las de Alan Bond, magnate de la televisión por cable, ambos nacidos en Sidney. A ello dedico el verano de 1.990. Coetáneos del primero, el más internacional de los líderes (viejos amigos, periodistas y profesores), me explican en la Isla-Continente, antípoda de nuestra Península, su comportamiento y sabiduría precoz a la hora de configurar empresas comunicativas revolucionarias (en su país natal posee veintisiete periódicos y dos cadenas de televisión). Este no era ya un «recién accedido», sino persona que había echado los dientes en el sector.

El «alertalismo» y enorme capacidad de asumir los imprescindibles «riesgos» de cualquier tipo -financieros, políticos, judiciales, diplomáticos y tecnológicos-, características de la controvertida vida de Murdoch, reaparecen en el contexto de su actual ambición de preparar una gran plataforma europea de televisión digital. Insatisfecho de poseer la cadena británica BSkyB, donde además tendrá competencia de la televisión númerica digital y su televisión por cable, persigue ahora nada menos que el dominio de todo el mercado audiovisual del Viejo Continente. 
La ruta se enriquece mucho en Norteamérica, ya que Canadá revoluciona la televisión interactiva y EE.UU. alberga una docena de conglomerados mundiales. Así conocí, desde ese momento, los balbuceos de la ambiciosa empresa Cable News Network, Inc., de Ted Turner, en Atlanta, ensayada, dentro del ámbito de televisión, en Nueva York, a través del canal CNN, de «24 horas al día de noticias», los «365 días del año», que dejó perplejos a las restantes compañías mediáticas. Siendo de agradecer al magnate la generosidad de permitirme acceder a la interioridad del negocio y dialogar una y otra vez con sus equipos redaccional y administrativo, circunstancia que permite contrastar el casi desprecio de los «tradicionales» del negocio de la comunicación estadounidense, respecto del talento, valentía y dotes persuasivas del líder «recién llegado»al sector (era entonces conocido multimillonario del petróleo).

Dándome cuenta muy pronto de que su corporación tenía visos de triunfar, aposté en mi trabajo universitario por el éxito. En efecto, transcurrido un trienio de verdadero «suspense», Turner consigue llenar de estudios CNN los restantes Estados de la Unión, para saltar, siempre de forma escalonada a otros continentes -la incursión en Extremo-Oriente estos meses redondea el afán. Todos ellos convertidos en elementos generadores de una información ignorada hasta entonces, paladín en «instantaneidad»y «mundialización», a nuestro entender de alta eficacia (ORIVE, 1.994).

Rayan la veintena de magnates, en su origen de prensa, radio y televisión, y más próximos a estos días, de los grandes conglomerados comunicativos, que son quienes refuerzan la afirmación definitiva del vocablo y están siendo estudiados en la ruta produciéndome una de las más grandes satisfacciones empíricas encontrar en ellos el factor común de un carisma especial para moverse en el ámbito de la creación intelectual, inmaterial y saber incorporar nuevas dinámicas, equipos directivos y profesionales, como si del «feed-back» resultante naciera una energía de voltaje exponencial.

Nuestros magnates heredan la experiencia de quienes les precedieron a principio de siglo e introducen rasgos hasta ahora impensables en el perfil, aunque enraizados en la filosofía tradicional,resumida en escasas líneas por el adelantado de la industria del automóvil, Henry Ford, a principios de siglo: «poca gente osa lanzarse a los negocios, porqe en el fondo de sí mismos se dicen: ¿por qué lanzar tal producto al mercado, si ya hay alguien que lo hace? 
Yo, en cambio, me he dicho siempre: ¿por qué no hacerlo mejor? Y eso es lo que hice» (POISSANT y GODEFROY, 1994, p. 45).

En esta compleja dinámica, donde se anclan las diferentes extracciones y talantes de los magnates del hipersector, no pueden hurtarse los acuciantes requerimientos que también pesan sobre los políticos, de descubrir y ensayar nuevas formas de operar. Parlamentos y Gobiernos vienen obligados a actuar de forma inteligente respecto los grandes conglomerados comunicativos para que, en medio de las lógicas garantías democráticas, promover sus intereses, ya que impactan en la raíz del desarrollo de los países y, en la medida adecuada, acelerar la liberalización de las telecomunicaciones y las manifestaciones de la libertad de expresión.

El cúmulo de datos obtenidos descubre que la mejor manera de tomar el pulso de las revoluciones expuestas es la exploración de las motivaciones y realizaciones de los magnates. En sus conglomerados hierven los frutos de la conjunción tecnológico-financiero. Se analizan experiencias y productos novedosos. Así que la pregunta, ¿es suficiente con reducir el estudio de las transformaciones telecomunicacionales al específico de los magnates?, puede responderse afirmativamente porque en este ámbito, a diferencia de los sectores tradicionales del automóvil, la aviación, el petróleo, etc.,en el nuestro de industria del pensamiento, lo gordiano son las condiciones humanas, inventiva y excepcionalidad del líder.

\section{Nervio financiero de las NTI.}

De la interrelación turbulencias tecnológicas 1.980-1998, experiencia en la formación de los grandes conglomerados y energía propia de los magnates, aflora a la superficie el nervio troncal financiero de las NTI. Es decir, las cuantiosas cifras de dinero en curso. No siendo oportuno enmascararlo, como hacen, KING y SCHNEIDER (1.992), una vez acoger la idea de muchos economistas, para quienes, el desarrollo tecnológico estudiado surge de la interacción de las fuerzas económicas y es, como si dijéramos, uno de los músculos de la mano invisible de Adam Smith. Uno de los músculos, quizá, pero hoy menos de «mano invisible», porque está a flor de piel en el ambiente.

Cuanto se lleva dicho aconseja verlo en actitud crítica y en el contexto de la «globalización», gran tema mundial, desde 1.997, en los negocios y finanzas. Un proceso no nuevo, pues es tan antiguo como el mismo comercio; lo que si ha sucedido es su producción estos años con gran aceleración. 
Al menos, la evaluación del fenómeno sobre los efectos en paises del Tercer Mundo, arroja un saldo inquietante. Por eso atribuir precipitadamente a la globalización de la información y la creación de megagrupos, el rasgo hegemónico del final de siglo, llamado a alumbrar una sociedad distinta apoyada sobre los pilares de la comunicación y los mercados de escala, exige un amplio debate.

Sin embargo, a poco se analicen los resultados, la interjección industria informática avanzada (en las dos fases citadas), entretenimiento (vídeo, cine y televisión) y la comunicación propiamente dicha (mediática), asustan las grandes dimensiones financieras, necesitadas para estar a la altura de ella. Fácil es comprobar la sorprendente plétora de gestores de redes, empresas editoriales, periodistas y proveedores involucrados. Junto, y como razón de ser, la inmensidad de consumidores dispuestos ahora, por ejemplo en el caso norteamericano, a pagar del orden de 35 a 40 dólares al mes para recibir en casa todo tipo de distracciones a través del cable.

Dentro de ese entramado a nadie puede extrañar que se hable tanto de imágenes y sonidos, propios del mundo de ficción y cosas parecidas, anticipadas en las páginas de William GIBSON, en su novela de ciencia ficción (1.984), donde utiliza, en primicia, el término «ciberespacio», universo saturado de televisiones, monitores de ordenador, CD-ROM, videojuegos, discos láser, equipos estéreos y auriculares. Bien a las claras representativo de un nuevo peldaño en la escala de la comunicación, cristalizado en la praxis mediante el acceso televisivo «a la carta», con un menú nutrido de películas de vídeo, servicios de telecompra, teleeducación, videojuegos, sanidad y el final, «Internet» en su primera y segunda edicción.

Este último, una vez analizado su crecimiento exponencial en poco tiempo, consagra la importancia del peldaño. «Internet» empieza a ser el mayor fenómeno de comunicación aparecido y la prospectiva avala su conversión en la base del intercambio de información que recibirá el alumbramiento del tercer milenio. Encima por ser tan valioso para los negocios y la formación, quien controle esta red tendrá en sus manos el control de la publicidad, soporte decisivo de la vida mediática.

Juntos, todos los medios mencionados, ofrecen ya inéditas oportunidades, en apariencia excesivas, eclipsantes, configuradoras a mi entender de otra sub-era, calificable de ensayo-error, de claro-oscuro, urgida del cultivo de una nueva sensibilidad personal y colectiva. No obstante, al final, serán las «redes» de ordenadores, en el decir vulgar de equipos de «software», nece- 
sarios a la hora de ponerlas en marcha, quienes de verdad impulsarán la industria informática, y posibilitarán las soluciones multimedia. El «software», de ser un producto informático, empieza a convertirse en un producto industrial.

Una evolución así de fascinante necesita del referente continuo de los datos prospectivos sobre las NTI y los grupos comunicativos, su enorme poder y control de la sociedad, partiendo de aquella distinción efectuada por nosotros, al iniciarse la década de los «ochenta» (ORIVE, 1980, ps. 76-143), donde establecimos diferencias entre poder de información y poder de comunicación. Entonces era intuible que el desarrollo tecnológico acelerado iba a demandar economías de escala a la hora de construir industrialmente unos canales -elemento decisivo del proceso de comunicación-, cada vez más sofisticados y unos líderes empresariales fuera de lo común. La formación de los grandes grupos multimedia estaba contado.

Fueron aquellas economías quienes aseguraron la optimización de las redes y en paralelo la multiplicación de la presencia y penetración de los mensajes mediáticos, en la sociedad de las informaciones, adjudicación cada vez más justificada, donde, como dijimos, se hace imposible aislar los fenómenos de la gestación, y la eficacia del impacto tecnológico, de los generales que atraviesa la humanidad, en cuanto integran un mismo hecho. Desde esta almena, retroalimentada por la «interactividad», ¡qué difícil deslindar el hecho político del hecho comunicativo!, pues, este último ha pasado a ser elemento originado del poder, arrostrando el naciente riesgo de que, junto a Gobiernos que saben interpretarlo en clave democrática, existen otros que lo usan en detrimento de la ciudadanía.

Quizá en la anterior década fuera posible tipicar las relaciones mediosgobierno, como hicieron JEFFRES y PERLOFF (1.986, p. 273) en términos de «modelo de intercambio», donde ambos dan algo y reciben algo a cambio, influyendo cada uno en el otro y no siendo ninguno totalmente independiente. Pero hoy, la endogénesis que nosotros sustentamos, por ir más allá, expone a cualquier gobierno al trance de saber preveer, en cada instante, el alcance de esas relaciones en términos de opinión pública. Ser exquisitos en garantizar los libres flujos de información.

Por ejemplo, a raíz de la II Guerra Mundial, es aceptada la prepotencia de los monopolios estatales de radio y televisión, en algunos de países europeos, aunque con diferencias significativas, según cada talante democrático. Mejor diría la funcionalidad del binomio medio audiovisual-sociedad, 
en la forma esbozada en primicia en la bibliografía española (ORIVE, 1.978, ps 231-234). Sin embargo, los avances en las telecomunicaciones, fuerzan a suavizar las relaciones y, poco a poco, su liquidación en los países más sensibles al avance liberalizador. El más reciente el de la radiodifusión austriaco (31-3-1.998), aunque manteniendo intacto el monopolio de televisión.

España, permítase una breve alusión, fue muy lejos en la utilización férrea del monopolio estatal de televisión (en radio existió de menos a más concurrencia con las cadenas privadas), dando espaldas al pueblo y la Prensa que lo considera una «agresión» a la libertad de expresión. Incluso, después de su destrucción, tras la tarde y forzada concesión de tres cadenas privadas, como tampoco ha sido capaz este gobierno de crear un marco adecuado para la nueva convivencia entre ellas y el Ente Público, persiste el «enfrentamiento» entre ambos, ante el tremendo caos financiero, la inadmisible competencia en publicidad comercial y la obsesión política de hacer de TVE, con el viejo modelo, el principal grupo estatal de comunicación audiovisual.

Posponemos hasta mejor ocasión la desaparición del más poderoso monopolio del ramo, la Compañía Telefónica Nacional de España, privatizada el pasado año, según los dictados liberalizadores de la Unión Europea (UE), y estos días, aunque con excesivos resabios, objeto de una gigantesca ofensiva para convertirla en un conglomerado mundial (tele-mediaredes).Pretensión en principio loable, aunque los latidos del desequilibrio hipopolítica comunicativa estatal y hiperpolítica gubernamental ansiosa por influir en cuantos instrumentos y medios de difusión estén a su alcance, puede empañar algo el renacimiento del nuevo modelo.Por su parte esa conducta oficial, si no la contrarrestan los accionistas, podría terminar en breve con un «boomerang» sintomático.

\section{La prospectiva, elemento del proceso.}

Abiertos al nuevo escenario, es conveniente no perder de vista la historia de la ciencia, saber «si, en efecto, las innovaciones esbozadas son o no revolucionarias, per se, o más bien proceden de la evolución de tecnologías anteriores». Siguiendo de cerca el cambio traumático expuesto en páginas anteriores, parece difícil el desenlace, aún a pesar de los esfuerzos en esta dirección de poderosos «cerebros mundiales» y el quehacer de algunas investigaciones, sensibles a los fundamentos prospectivos, asumidos en escaso número de industrias transnacionales y Universidades. 
Entre tales investigadores, manejados en algunos trabajos anteriores -caso de WAGNAR (1.995), existe la creencia de que «los escenarios demuestran cómo unos acontecimientos están moldeados por otros anteriores». Incluso,la existencia en nuestros días, de parte de la «evidencia bruta que los historiadores posteriores utilizarán para explicar el siglo XXI, igual que necesitamos todos datos anteriores al 1.800 para componer una imagen del siglo XXI».

Bastante antes, casi a la vez de iniciada la Ruta de los Magnates, decidimos incorporar algunos aportes de la ciencia prospectiva a la línea de investigación en curso.

Considerarla elemento del proceso de exploración de las sucesivas fases teóricas y operativas del universo comunicativo, era insosloyable, máxime tratándose de un hipersector que gira en torno a la aceleración, palabra mágica, granítica, causa primera de toma de decisiones súbitas, discutibles $\mathrm{y}$ arriesgadas.

El enriquecimiento que conlleva la predicción de acontecimientos sobre las principales tendencias de los diferentes procesos evolutivos de la información, analizados en el Informe del Japan Computer Usage Development Institute (JACUDI), de los años 1.972-74 (ORIVE, 1.983, ps. 39-42), hace más asequible cualquier decisión. En especial el cuarto (1.980-2.000), que perfila el objetivo (satisfacción), el sistema de valor (realización personal), el sujeto (individuo), el objeto (comportamiento humano), la ciencia base (ciencias del comportamiento) y el modelo de información (creación intelectual).

\section{Nuevos tipos y comportamiento comunicativos.}

No hemos hecho más que iniciar el ascenso del peldaño, y ya se vislumbra un giro copernicano de la noción tradicional de relaciones entre auditorios tradicionales y organizaciones, puesto que los primeros, de meros recipendiarios o consumidores de mensajes, poco a poco, pasarán a ser en cierta medida, también proveedores, asegurando flujos informativos, opinativos y recreativos en dos direcciones. En fin, el sueño dorado de la anhelada comunicación de «doble sentido», y personalizada totalmente.

Esa estrategia de suministrar contenidos, en líneas generales suena muy bien, e incluso impresiona en los ambientes afectados, aunque resulte grave que, a estas alturas, no se piense con rigor, sobre los límites sufridos a recipendiarios y audiencias tradicionales, que no disponen del suficiente tiempo real de «exposición» de mensajes, ni del criterio deseado, ante la inabarcable oferta potencial de canales y demás productos audiovisuales. 
El atractivo de esta problemática es una de las causas de la inquietud de los expertos (filósofos, sociólogos, psicólogos, pedagogos y éticos) por el impacto cruzado de la generación de las innovaciones tecnológicas punteras, ante su necesidad de satisfacer la demanda de «nuevos tipos» de comunicación, capaces de estimular y consolidar «nuevos comportamientos» individuales o colectivos, a la vez que modificar los modelos de funcionamiento de la sociedad global.

Este impacto cruzado es lógico que maneje operadores de cable, empresas de telefonía y compañías informáticas, e impulse lo que, aún sin vivir la era digital, llamada a agravar los efectos, Marshall McLUHAN denominó «aldea global» de las telecomunicaciones». En ella, millones de personas viven atrapadas dentro de celdas en una enrevesada «tela de araña», sobrevolando desiertos, cordilleras y océanos, aunque - he aquí lo más doloroso-, excesivas veces en circunstancias de indefensión, presos del bombardeo de la «artificialidad» de mensajes alienantes, distantes de cuanto en realidad sucede en la vida ordinaria.

De manera oportuna también en otra cumbre G-7, fue Francia quien, tras denunciar el peligro de la uniformidad cultural y el empobrecimiento de la creación artística, que tanto vienen obstaculizando ese paso, exigió, con energía, la puesta en marcha de una política de diversidad cultural. Voluntad que lleva implícita una reacción frente al desarrollo autónomo de las NTI y sus aplicaciones inmediatas, creadoras de una coyuntura similar a las de la televisión y el cine, víctimas del predominio de los agresivos productos estadounidenses en detrimento de los europeos.

Como la tendencia crece exponencialmente no les queda más remedio a los cerebros aludidos que esforzarse por «recentrar» y «armonizar» la sociedad, a través de la síntesis. Los magnates mundiales, más sensibles que nadie al asunto, empiezan a pensar en ello, conscientes de que va a salir muy rentable una relación distinta con los usuarios. Es cierto que, junto al increíble salto en la investigación tecnológica, las ciencias del comportamiento, interdisciplinarias de suyo, son las más llamadas a suministrar bases para modificar la visión de esa relación.

Todo ello, claro está, enfocado a las primeras etapas de la vida y distanciándose de las hipótesis reduccionistas mediáticas y de ciertas teorías del aprendizaje que tanto vienen contribuyendo a «descentrar» la sociedad. En el Foro sobre «los jóvenes y los medios de comunicación de mañana», celebrado el pasado año en la UNESCO (21-27/4-1997), la profesora fran- 
cesa Geneviève Jacquinot, tras denunciarlas, porque no están «adaptadas al contexto de la sociedad tecnológica», y resaltar la existencia de una inteligencia televisional de los jóvenes, termina pidiendo sea sustituida la pregunta tradicional, ¿qué hacen los medios de comunicación al público?, por la inversa, ¿qué hace el público con los medios de comunicación?.

Nuestro niño, inmerso de plano en el horizonte audiovisual, descrito al principio, atosigado de «posibilidades para aprender», demanda del conjunto social el establecimiento de una «complementariedad entre esos nuevos instrumentos y lo que se hace tradicionalmente en la familia y la escuela», defendida en el citado Foro, por Xavier Gouyou Beauchamps, presidente de France Télévision. Nosotros, sin embargo, vamos un poco más lejos y preconizamos el viraje en las estrategias de tratamiento en el sentido de que sean los propios medios quienes incorporen las causas de su problemática.

Parece hasta inconcebible que muchos países -España entre ellos-, ignoren estas tendencias, cuando el «handicap» más sufrido en la era digital, consiste en no saber que el niño (y el adolescente incial), dentro del horizonte mental del sujeto receptor, es el verdadero «rey» del sector mediáticotelecomunicacional. Quien puede «reactivar» sin cesar todo tipo de auditorios. Para superarlo han de resumirse hábilmente los fundamentos y metodología de las ciencias del comportamiento, ya que las de la comunicación, tan en boga, únicamente aportan un ingrediente, y no el primero.

Lamentable es el riesgo en que incurren las organizaciones mediáticas, acogiendo, sin acompañar a la vez los resultados de las observaciones antes hechas, en sus páginas o programas, noticias sobre la «complementariedad» aludida coadyuvantes del distanciamiento, de la escasa eficacia y credibilidad de los mensajes, conformados con tanto esfuerzo, y raíz de la desconfianza en la relación informativa. La nueva estrategia sugerida va en esta dirección.

Habiéndose cubierto el espacio que nos habiamos trazado para el artículo, terminamos redondeando aquel pensamiento de un pensador japonés que decía «no poseo una filosofía, sino solamente nervios», y añadiendo por nuestra parte que se necesita de filosofía y nervios a la vez. 


\section{BIBLIOGRAFÍA}

a) Bibliografía citada

- JEFFRES, Leo W. y PERLOFF, Richard M. (1986): Mass Media Processe an Effects. Prospects Heights. Illinois, Waveland Press Inc.

- JOSHINO, Michael y RANGAN, Srinivasa (1996): Las alianzas estratégicas. Ariel. Barcelona.

- ORIVE RIVA, Pedro (1980): Diagnóstico sobre la información. Editorial tecnos. Madrid.

- ORIVE RIVA, Pedro (1983): La comunicación humano-social en la era del microordenador. Escuela de Estudios Sociales. Torrelavega (Santander).

- ORIVE RIVA, Pedro y otros (1994): Del Golfo Pérsico a los Balcanes. Dos guerra en la era multimedia. Editorial Complutense. Madrid.

- POISSANT, Charles A. y GODEFROY, Christian (1994): Los hombres más ricos del mundo. Versión española, Francisco Javier Aguirre. Iberonet, S.A. Madrid.

- STERNBERG, Robert J. (1997): La creatividad en una cultura conformista. Paidos Trad. Ferrán Meler. Barcelona, Buenos Aires, México.

- STRACHEY, John (1974): El capitalismo contemporaneo. Fondo de Cultura Económica. Trad. Francisco González Aramburo. México.

- THUROW, Lester C. (1996): El futuro del Capitalismo. Ariel. Barcelona.

- ZELDIN, Theodore (1997): Historia íntima de la humanidad. Alianza Editorial. Versión, José Luis Gil Aristu. Madrid.

b) Bibliografía complementaria

- BRESSAN, Albert y DISTLER, Catherine (1995): La Planeté relationnelle. Flammarion.

- BAIRON, Sergio (1995): Multimedia. Global Editora. Sau paulo.

- NEGROPONTE, Nicholas (1995): Being Digital. Alfred A. Knopf, Ic.

- NORA, Dominique (1997): La conquista del Ciberespacio. Edit. Andrés Bello. Trad. Carlos Gardino. Barcelona, Buenos Aires, México, D.F. Santiago de Chile.

- SCHWEITZER, David y GEYER, R.F. (1998): «Alienation Theories and De-Alienation Strategies» Science Review. 
- SIMONTON, D.K. (1975): «Sociocultural context of individual creativity: A transhistorial Time-series analysis», Journal of personality and Social Psychology 32, 1.119-1.123.

- WEISBERG, R. (1986): Creativity genius, and other myths. N.Y., W.H. Freeman Co. 